\title{
Teoría y praxis del discurso democrático en Marruecos desde una perspectiva de género: Malīka al-'Āṣimī ${ }^{-1}$
}

Theory and praxis of democratic discourse in Morocco from a gender perspective: Malīka al'Āṣimī

\section{Rocío VELASCO DE CASTRO}

Universidad de Extremadura

rvelde@unex.es

https://orcid.org/0000-0003-0377-4100

Recibido: 7/9/2018. Revisado y aceptado para publicación: 10/12/2018

Para citar este artículo: Rocío VELASCO DE CASTRO (2018), "Teoría y praxis del discurso democrático en Marruecos desde una perspectiva de género: Malīka al- 'Āṣimī” en Revista de Estudios Internacionales Mediterráneos, 25, 60-78.

Para acceder a este artículo: https://doi.org/10.15366/reim2018.25.004

\section{Resumen}

La escritora marroquí Malīka al-'Āṣimī (Marrakech, 1946) es fundamentalmente conocida como poeta, pero su contribución a la narrativa feminista y a la crítica literaria no ha sido traducida del árabe. En este trabajo se ofrece una semblanza biográfica de la autora y una panorámica de su producción que incluye el estudio de Al-mar'a wa iškāliyyat al-dīmuqrāțiyya siguiendo la metodología del análisis del discurso. En este ensayo al-'Āṣimī critica el escaso papel que ha tenido la mujer en las instituciones políticas del país magrebí.

Palabras clave: Marruecos, Feminismo, Literatura, Democracia, Malīka al-'Āṣimī

\section{Abstract}

The Moroccan writer Malīka al-'Āșimī (Marrakech, 1946) is essentially known as a poet but her contributions to feminist narrative and literary criticism are also significant, although they have not been translated from Arabic. This paper provides a biographical sketch of the author and an

\footnotetext{
${ }^{1}$ El presente trabajo se enmarca en el proyecto de I+D Ideología, texto y discurso: narrativas del cambio social en el Norte de África-IDENAF (Ref. FFI-2016-76307-R) dirigido por Juan Antonio Macías Amoretti (Universidad de Granada) y financiado por el Plan Nacional de Investigación, Ministerio de Economía y Competitividad y los fondos FEDER de la Unión Europea.
} 
overview of her production. It also includes a study of her essay Al-mar'a wa iškāliyyat aldìmuqrāțiyya following the methodology of discourse analysis. In this essay, al-'Āṣimī criticizes the limited role that women have played in Moroccan political institutions.

Keywords: Morocco, Feminism, Literature, Democracy, Malīka al-'Āṣimī

\section{Semblanza bio-bibliográfica de una feminista militante}

La defensa de los valores e instituciones democráticas desde una perspectiva de género discurre en el caso de Malīka al-'Āṣimī en torno a tres ejes: su actividad política como militante del Istiqlāl, su labor docente e investigadora, y su producción literaria en prosa y en verso. En todas estas facetas se percibe la influencia ejercida en su adolescencia por su círculo familiar. Nacida en Marrakech en 1946, es sobrina de 'Abd al-Qādir Ḥassan al-'Āṣimī, poeta y uno de los miembros fundadores del partido del Istiqlāl, e hija de Aḥmad b. al-Ḥassan al-'Āṣimī. Este último también mantuvo una estrecha vinculación con el partido y en las postrimerías del régimen colonial fue designado para dirigir la primera escuela femenina nacionalista de Marrakech.

Inmersa en la inestable coyuntura política y social de los primeros años del Marruecos independiente que desembocaron en los años de plomo, al-'Āṣimī inició sus estudios superiores en la Universidad de Marrakech, donde obtuvo su licenciatura en 1964. Tras ejercer unos años en la Secundaria, regresó a la universidad en la década de los ochenta para trabajar como profesorainvestigadora en el Institut Universitaire de Recherche Scientifique (IURS) de Rabat e iniciar su investigación de tesis doctoral. Durante este periodo compaginó su formación con una activa participación en la vida política y la publicación de sus primeros trabajos en revistas literarias.

Enfocada en la literatura, y más concretamente en el papel de la mujer en este ámbito, en 1987 presentó su tesis doctoral. Titulada al-Hikāya al-ša'abiyya fi Marrākuš (Cuentos populares de Marrakech), se trata de un voluminoso estudio en el que la autora realiza una remarcable tarea de compilación y análisis de la literatura popular. En concreto, centra su atención en los cuentacuentos y narradores que se dan cita en la bulliciosa plaza Yamaa el-Fna. Así, partiendo de un enfoque eminentemente local, con sus particularidades y semejanzas respecto a la literatura oral del resto del país, la autora emprende una revisión del trasfondo sociológico que se desprende de esta literatura con el objetivo de reivindicar el papel protagónico de la mujer (al'Āṣimī, 1987).

Al-'Āșimī incide en la importancia de la mujer como sujeto activo en tanto que hacedora, conservadora y transmisora de este rico corpus literario. Por este motivo, la publicación de la tesis contribuyó, por un lado a revalorizar un legado cultural que hasta entonces no había gozado de demasiada atención por parte de la intelectualidad marroquí y por otro, a analizar la génesis de los valores culturales y religiosos preservados en la memoria colectiva de la sociedad.

Esta última cuestión constituye la piedra angular de su análisis ya que, en tanto que dichos valores acabaron consolidándose en torno a una memoria nacional compartida a través del cuento 
popular, el carácter patriarcal de la sociedad de la que dimanan perpetuó la subordinación femenina y su cosificación en roles inmovilistas y estereotipados.

En su estudio, la autora desarrolla dos ideas fundamentales. En primer lugar, el anacronismo que supone extrapolar al presente los cimientos de la sociedad patriarcal medieval en la que se desarrollan las historias narradas. $Y$ en segundo término, la activa participación femenina en el proceso de creación, re-creación, innovación y transmisión oral del cuento popular. Todo ello requiere de una creatividad que reflejaría también la valiosa labor de la mujer marroquí como narradora-autora de textos literarios.

Esta cuestión le sirve para introducir otro interesante debate en torno a la división entre tradición popular escrita, mayoritariamente de autoría masculina, y la oral, exclusiva prácticamente de las mujeres. Además de defender el papel protagónico de lo que denomina "cultura de las mujeres" (al-'Asimi, 1987: 106) en la conservación de la literatura oral y en su transformación en un patrimonio cultural común a toda la sociedad, también reivindica su presencia y actividad en la literatura escrita. Es en esta última vertiente en la que ella misma, a través de su producción, decide romper con ese techo de cristal impuesto a las mujeres.

Consciente de que la génesis de la actual situación de desigualdad reposa en los componentes identitarios de la cultura tradicional marroquí y en sus efectos en el proceso histórico de formación de la personalidad intelectual y cultural de la sociedad, al-'Āșimī no sólo rebate el anacronismo de algunos de estos valores. También señala la ausencia de otros elementos fundamentales en la configuración de dicha identidad. Con ello denuncia una imagen simplista y discriminatoria respecto a la amazighidad ${ }^{2}$.

En el plano personal, su posición se explicaría por su ascendencia amazigh, lo que añadiría aún más interés a la labor desarrollada por la autora en tanto que representante de dos colectivos discriminados durante más de medio siglo de historia del Marruecos independiente: las mujeres y los imazighen.

Por ello resulta especialmente interesante el compromiso que adopta la autora quien, pese a expresarse en árabe, reivindica la amazighidad como elemento consustancial a la riqueza de una identidad marroquí plural y heterogénea. La pertinencia de su demanda se refleja en la falta de implementación del artículo 5 del texto constitucional de 2011, actualmente en vigor, en el que se reconoce la co-oficialidad de dicha lengua, sin que hasta el momento dicho reconocimiento se haya trasladado a los ámbitos jurídico, social, cultural y económico.

Acorde con las reivindicaciones expuestas en su tesis, al-'Āșimī ha tratado de inculcar a sus estudiantes esta visión y la autocrítica en torno al legado literario durante las décadas que ha ejercido como profesora de literatura árabe en las Universidades Cadi Ayyad de Marrakech Mohamed $\mathrm{V}$ de Rabat. Paralelamente a esta dedicación, logró iniciar y consolidar una carrera literaria como poeta hasta convertirse en una figura reconocida dentro y fuera de Marruecos.

\footnotetext{
${ }^{2}$ Para despojar al lenguaje de cualquier impronta colonial que representa la etimología derivada del término "bereber" o "beréber", se utilizan los vocablos "amazigh" (plural "imazighen") para el colectivo, "tamazight" (femenino de "amazigh") para hacer una referencia genérica a la lengua y sus diferentes variedades, y "amazighidad" para los rasgos identitarios que componen la idiosincrasia de esta población.
} 
Además del mundo literario y de su vocación académica, la militancia política de su entorno también influyó en su trayectoria. La vinculación familiar con el Istiqlāl hizo que Malīka al-'Āṣimī militara desde joven en la sección femenina del partido. Como parte de su programa de reformas, los partidos nacionalistas como el Istiqlāl o el Hiizb al Ișlāḥ al Wațanī (Partido Reformista Nacional) contaban con secciones femeninas desde las que, emulando a sus matrices masculinas, se organizaban mítines, manifestaciones y una serie de actividades de carácter fundamentalmente social y cultural. Sin embargo, una vez obtenida la independencia, esta militancia fue relegada a un segundo plano. Consideradas rivales a la hora de ocupar puestos de responsabilidad, las antiguas compañeras de lucha se convirtieron en un obstáculo más que debía solventarse para lograr el control de los destinos del país (Velasco, 2017: 67-69).

Consciente de que esta hegemonía política y sus extensiones al ámbito social y cultural se legitimaba en el modelo patriarcal sustentado en la Mudawwana, al-'Āșimī decidió liderar y compartir con otras tantas compañeras, dentro y fuera de la agrupación, una dura batalla por la igualdad. Lejos de desentenderse del partido, abogó por cambiar desde dentro esta tendencia.

Convencida de que la política seguía siendo una herramienta fundamental para concienciar y luchar por una sociedad más igualitaria, la autora expresa reiteradamente la necesidad de combinar la teoría con la praxis y da ejemplo de coherencia presentando su candidatura a las elecciones al Parlamento. Esta última fue aceptada en 1976, aunque no consiguió ser elegida como diputada hasta dos décadas más tarde.

En 1996 se convirtió en una de las primeras mujeres que representaba un distrito local en el Parlamento y desde entonces ha sido la única en mantenerse durante dieciséis años como teniente de alcalde de una gran ciudad, como es Marrakech (Boum, 2016: 68). A este logro sumó, años más tarde, su incorporación como miembro del comité ejecutivo del Istiqlāl.

En el ejercicio de dicho cargo, que sigue ocupando en la actualidad, ha hecho gala de una gran coherencia en la toma de decisiones de muchos de los temas abordados, algunos de ellos bastante controvertidos. Así, se ha mostrado públicamente partidaria de la línea aperturista y modernizadora impulsada por el entonces nuevo secretario general del partido, Abd al-Hamīd Šabbāț. Un apoyo que no ha sido óbice para que continúe denunciando el papel secundario que continúa desempeñando la mujer en la vida política, económica y social marroquí.

Tras haber revalidado su escaño, en una entrevista concedida en 2012 para la Unión de Escritores Marroquíes se mostraba tajante al respecto. Profundamente insatisfecha con las reformas introducidas, expresaba su perseverancia en "trabajar dentro de los valores democráticos con todas las partes para construir la justicia social" (Belqāsim, 2012). Y para ello vuelve a señalar la clave que hará posible llegar a ese modelo: "cambiar la mentalidad de la ciudadanía y que dicho cambio se refleje automáticamente en la conducta diaria" (Belqāsim, 2012).

La justicia social a la que se refiere al-'Āșimī parte de un presupuesto igualitario por el que la mitad de la población marroquí que representan las mujeres vea reconocidos los mismos derechos políticos, sociales, económicos y culturales que la otra mitad del país y lo que es igualmente importante, que dicha igualdad se aplique a todos los órdenes de la vida cotidiana sin excepción. Esta definición, en la que confluyen desde distintos enfoques y corrientes otras importantes 
defensoras del feminismo en Marruecos y en todo el mundo árabe, ha llevado a algunas escritoras a saltar a la arena política.

Dicha incursión se enmarcaría en una coyuntura de mayor visibilidad y participación efectiva de la mujer en los movimientos asociativos. Dos ejemplos ilustrarían esta evolución: la consolidación del liderazgo femenino al frente de numerosas asociaciones en defensa de los derechos humanos en general y de los laborales, jurídicos, culturales y lingüísticos en particular -entre ellos los del colectivo amazigh (Feliú, 2006: 273-286)- y el establecimiento de redes femeninas de colaboración (Benlabbah, 2001: 9-19; Olmedo, 2006: 267-293; Pérez Beltrán, 2001: 236-237 y Velasco, 2012: 659-670).

En esta línea, la reacción de al-'Āṣimī tras las protestas articuladas en torno al Hirāk en el Rif dio muestras de dicho compromiso. La represión con la que fue desmantelado el movimiento suscitó en la autora una dura crítica contra los responsables políticos. En un artículo del pasado 12 de junio de 2017, la autora definía la situación de "injusta, humillante e inhumana" y volvía a poner el dedo en la llaga al señalar los detonantes y sus responsables: el "cáncer de la corrupción y los abusos de poder cometidos contra una población cansada, indefensa y sin nada que perder" (al'Āṣimī, 2017).

No ha sido la única en alzar la voz mostrando su solidaridad con un colectivo en el que la amazighidad continúa siendo un rasgo distintivo de sus reivindicaciones. Por su claridad expositiva, su análisis del Ḥirāk constituye una de las mejores radiografías que se han hecho hasta el momento de los motivos que han llevado a los rifeños a levantarse para defender sus derechos en un movimiento pacífico y coordinado en el que, de nuevo, la mujer ha ocupado un lugar preponderante. De hecho, es uno de los aspectos en los que más incide la autora. Entre los abusos cometidos, se hace hincapié en la situación de riesgo de exclusión y sufrimiento en la que viven muchas mujeres en tanto que son víctimas de una triple ecuación: la pobreza, la violencia familiar y la policial.

En cuanto a su producción literaria, la primera incursión se remonta a la década de los setenta. La primera tentativa de desligarse ideológicamente del periódico al-Ālam, portavoz del Istiqlāl, tuvo lugar en 1973. En ese año, al-'Āșimī fundaba el semanario al-ljtiȳār, que como señala Benjelloun (1976: 11), constituyó un primer y meritorio, aunque frustrado, intento de independencia y libertad creativas. En cualquier caso, como destaca al-Wazzānī (1993: 277), al-'Āṣimī sentó un precedente al convertirse en una de las primeras mujeres editoras del país.

Como señala Fernández Parrilla (2014: 115), los años sesenta habían marcado un punto de inflexión en la vida cultural que afectó también a las revistas y supuso "la emergencia de una nueva generación política y literaria fuera del control del gobierno". A diferencia de otra conocida escritora como Janata Bennuna, quien en 1965 había fundado la primera revista marroquí de mujeres, Šurūq, al-'Āṣimī nunca concibió el semanario para un lector específicamente femenino.

Si bien mantuvo una estrecha colaboración durante años con la conocida publicación al-Taqāfa alMagribiyya, no se decidió a publicar sus poemas hasta finales de los años ochenta. Una circunstancia sin duda explicable porque dicho periodo coincide, grosso modo, con los llamados años de plomo. Unas décadas negras en las que la maquinaria represiva del Estado, incluyendo secuestros, torturas y detenciones arbitrarias, vulneró reiteradamente los derechos y libertades más fundamentales de la ciudadanía marroquí. 
Al-'Āṣimī reconoce la influencia en su escritura de grandes figuras poéticas de la literatura árabe clásica. Entre ellas, como recoge Belqāsim (2012), 'Abbās Ibn al-Aḥnaf (n. 750 - m. 809) o Abū alṬayyib Aḥmad ibn Hussayn (al-Mutanabbī, n. 915 - m. 965). Pero también se percibe, como expone Berrada (2008: 239), una ruptura con los modelos e imágenes clásicas como parte de su lucha personal por hacerse con una voz propia no sólo en el panorama literario, también en escenarios y realidades consideradas tradicionalmente masculinas.

Derivado en parte de lo anterior, la segunda característica es que Malīka al-'Āșimī no se expresa en la lengua del colonizador. Escribe en árabe, por lo que han tenido que ser escritores francófonos como Abdelmajid Benjelloun (1976: 15) o Abdellatif Laâbi (2005: 48) quienes hayan traducido algunos poemas al francés. Respecto a su obra en castellano, contamos con algunos poemas traducidos por compañeros escritores como Lamiae el-Amrani (2007: 266-267) y Larbi el-Harti (2008: 43), o traductores como el hispanista marroquí Abdellatif Zennan (Reyes y Zennan, 2007: 46-49), además de la traducción castellana de la antología del mencionado Abdellatif Laabi (2006).

Hasta el momento, cuenta en su haber con los siguientes poemarios: Kitābāt jāriŷ aswār al-'ālam (Escrituras más allá de los muros del mundo) editado en Bagdad en 1987 y reeditado al año siguiente en Casablanca (al-'Āṣimī, 1988a); Așwāt ḥanŷara mayyita (Las voces de una garganta muerta, al-'Āșimī, 1988b); Šay' la-hu asmā' (Aquello que tiene nombres, al-'Āșimī, 1997); Dimā' alšams (La sangre del Sol, al-'Āșimī, 2001a); Kitāb al-'așf (El libro de la tempestad, al-'Āṣimī, 2008); y Ašyā' tarāwada-hā (Cosas que te seducen, al-'Āṣimī, 2015).

Su obra más divulgada y comprometida, La sangre del Sol, está escrita en verso libre y en ella intenta reflejar sus sentimientos más íntimos y sus preocupaciones. Esta dimensión personal se aúna con una visión colectiva a través de la reivindicación de una libertad que lleve a la mujer marroquí a desvincularse de la represión que padece en ambas esferas, la pública y la privada, la social y la familiar. Así se desprende del poema siguiente (El-Amrani, 2007: 266):

\section{EL HUMO}

Las tardes me ahogan

Y por mí se iluminan.

Yo enciendo mi sol

Y su claridad me abruma.

Persigo los vientos

Para que extingan mi fuego

$Y$ me reduzcan

$A$ un cuerpo

De humo. 
La eterna lucha contra los elementos que sumen a su país y a sus mujeres en esta situación de injusticia y miseria, es representada en el poema "Acorazado" (El-Amrani, 2007: 266-267; Laabi, 2006: 87) ${ }^{3}$ :

\author{
ACORAZADO \\ Ensillo \\ mis barcos \\ mis acorazados \\ en la proa de las olas \\ y entro \\ en la batalla del diluvio \\ Lucho \\ tras las montañas de la muerte \\ hasta que se apaciguan \\ y me apaciguo \\ o me desintegro \\ cuerpo \\ abrasado \\ por el látigo \\ del viento.
}

Como puede colegirse, la autora se sirve de los elementos de la naturaleza, a los que dota de un nuevo significado dentro de un universo propio, pero al mismo tiempo representativo de otras mujeres. Por otra parte, y desde el punto de vista de la semiótica poética que describe Greimas (1976: 16-29), la correlación entre el plano de la expresión y el del contenido, entre el significante y el significado que establece al-'Āṣimì en los dos poemas mencionados supone sin duda una ruptura.

En consecuencia, es una mujer quien toma el mando de su cuerpo y de sus acciones. También de sus palabras, que emplea en ocasiones con la misma fuerza y virulencia de sus imágenes en contra de esa realidad impuesta ante la que se rebela para liberarse. $Y$ es una mujer quien interpreta la azora 19 del Corán en el poema de homónimo título y la dota de un nuevo significado al lenguaje religioso para hablar de su cuerpo y sus sentimientos (Laâbi, 2005: 48).

La intencionalidad de estos y otros versos, con "Miseria" como exponente más significativo (al'Āṣimī, 1988: 50; Velasco, 2017: 660), podría interpretarse en la clave desafiante a la que se refiere Dabashi (2012: 168-169) en su análisis sobre el poder del arte para revertir o al menos cuestionar el pensamiento ideológico sobre el que se basan los regímenes nacidos en época post-colonial y sus políticas abusivas y discriminatorias.

Para finalizar este recorrido, si bien es cierto que no ha suscitado tanto interés, conviene mencionar su obra en prosa. Al-'Āșimī es autora de numerosos artículos, casi siempre relacionados con la condición femenina, así como algunos trabajos sobre crítica literaria y literatura marroquí contemporánea. Véanse como ejemplos su panorámica sobre la literatura marroquí (Asimi, 1981:

\footnotetext{
${ }^{3}$ Se ha optado por la traducción que aparece en la antología de Laabi, que presenta algunas diferencias en los versos 1, 4, 9 y 10 con la que ofrece el-Amrani. Se ha traducido "Sello", mientras en Laabi aparece "Ensillo"; "la nariz de las olas" es para Laabi "la proa"; y el verbo elegido por el-Amrani es "aplacar" en lugar de "apaciguar".
} 
405-408) y su ensayo Naḥnu wa as'ila al-mustaqbal (Nosotros y las cuestiones de futuro, al-'Āṣimī 2001), en el que realiza un pormenorizado estudio acerca del mundo intelectual en Marruecos. Asimismo, y desde 2005, se encuentra inmersa en la elaboración de una enciclopedia de la cultura popular (Jay, 2005: 54), sin que hasta el momento nos conste que haya concluido o se haya presentado.

\section{Teoría y praxis del discurso democrático en Marruecos}

En 1991 Malīka al-'Āșimī publicó el que hasta el momento es su único trabajo dedicado a analizar el papel de la mujer en el sistema político marroquí. Titulado al-Mar'a wa iškāliyyat aldīmuqrāțiyya. Qirā'a fí al-wāqi' wa al-jițāb (La mujer y la problemática de la democracia. Estudio de la praxis y el discurso, al-'Āșimī, 1991), alberga pocas dudas sobre su intencionalidad y contenido. A lo largo de sus 108 páginas, el ensayo se centra en dos aspectos. El primero, la escasa presencia y participación de la mujer en el diseño y ejecución de las reformas políticas y sociales emprendidas en el país magrebí durante los primeros años de transición política y modernización, incluyendo su ausencia en la práctica totalidad de las instituciones creadas a tal efecto. Y en segundo término, vincula esta dinámica con la vigencia del modelo tradicional sobre el que se sustenta la sociedad marroquí, este último de honda raigambre patriarcal y en consecuencia discriminatorio para la mitad de la población.

Desde la década de los setenta, la participación de las mujeres marroquíes en el terreno literario y académico, así como su presencia en la esfera pública fue en aumento. Sin embargo, como se ha comentado en líneas anteriores, en el ámbito político las primeras mujeres que pudieron acceder al Parlamento no lo hicieron hasta la década de los noventa. Incluso hoy en día su presencia resulta cuantitativa y cualitativamente minoritaria en el conjunto de la clase política dirigente. Como refleja la obra, las consecuencias de esta situación adquieren especial importancia si tenemos en cuenta el alcance de las decisiones políticas en ámbitos como el cultural-educativo y el jurídico-social.

En este sentido, la reflexión de al-'Āșimī no sólo supone una interesante radiografía de la situación política marroquí en un momento clave como fue la salida de los años de plomo, también constituye una acertada mirada a la piedra angular del proceso de modernización y democratización: la lucha contra la discriminación de género.

\section{Análisis de la obra: trasfondo histórico y marco teórico}

El momento elegido para la publicación de la obra, 1991, no resulta casual. El país se encontraba inmerso en el inicio de un proceso de transformación a todos los niveles, especialmente notorio en el campo político, económico y social. A principios de los años ochenta la economía marroquí había tocado fondo. El paro subió, el valor del dirham cayó notablemente y se produjo una fuga de capitales (Nsouli et al., 1995: 46).

La crisis económica obligó a poner en marcha un riguroso plan de ajuste estructural y a adoptar nuevas dinámicas internacionales fruto de la globalización. Para pagar la deuda externa, el Fondo Monetario internacional y el Banco Mundial impusieron en 1983 una serie de recortes en sanidad 
y educación y el cese a la contratación de funcionarios. También se recortaron las subvenciones a los productos de primera necesidad, lo que dio lugar a las conocidas como Revueltas del Pan con dos momentos clave: 1984 y 1990, y ambos con ciudades de la región norte como Nador o Tetuán como focos más multitudinarios. A estas protestas se sumaron otra serie de huelgas y manifestaciones, muchas de las cuales fueron lideradas por los sindicatos y las cámaras de profesionales, que se sucedieron por todo el país (Pérez Beltrán, 2001: 233-234).

Entre las contrapartidas a estas ayudas externas, el monarca alauí adoptó el compromiso de adoptar una serie de medidas aperturistas y la implementación de una reforma política tendente a la instauración de unas bases sobre las que habría de sustentarse un régimen tendente a la democratización de sus estructuras y funcionamiento.

En este proceso de liberalización, la creciente movilización de la sociedad civil marroquí dentro y fuera del país desempeñó un papel importante. Como menciona Pérez Beltrán (2006: 9-23) existe una estrecha relación entre el desarrollo de la sociedad civil, a partir de los años ochenta, y un mayor acatamiento de los derechos humanos fundamentales y de mayores cuotas de libertades. Los acontecimientos de estas últimas décadas han confirmado esta tendencia, aunque también las disfunciones y el inmovilismo de un sistema que dista mucho aún de considerarse plenamente democrático (Parejo, 2005: 77-102; Velasco, 2013: 111-168 y 2016: 219-254).

En 1991 el país se encontraba en los albores de este proceso, por lo que parece acertado utilizar el concepto de transición pre-democrática acuñado por Benmsessaoud Tredano (2006: 51). Fue el primer paso de una serie de reformas que acabaron resultando más cosméticas que reales. Al menos tres ejemplos ilustrarían esta afirmación. La modificación introducida en el preámbulo del texto constitucional de 1992, en el que se incluyó la defensa de los derechos humanos pero no se llegó a aplicar. En segundo término, las esperanzas depositadas en las elecciones legislativas de 1993, que quedaron frustradas por el fraude perpetrado en los resultados. Y, en tercer lugar, la modificación de la Mudawwana en 1993 que quedó en un gesto simbólico de gran calado pero de nula efectividad en la mejora del estatus de la mujer. A partir de 1995, y sobre todo con la Constitución de 1996, la evolución, aunque muy limitada, comenzaría a percibirse.

Por otra parte, como señala Berrada (2008: 236) en su análisis de la producción literaria femenina en el norte de África, desde las independencias de sus respectivos países las mujeres han visto cómo la implantación de unos regímenes políticos no democráticos ha perpetuado la concepción patriarcal de la sociedad y su articulación en todos los órdenes de la vida pública. Esta situación habría desembocado en una clara discriminación y ha concienciado a las mujeres a luchar por sus derechos desde una perspectiva multi-dimensional, como se observa en la obra.

Desde el punto de vista literario, los escritos de Fátima Mernissi ya habían sentado un precedente en la denuncia de la condición de la mujer. La autora dio a conocer, en francés, una realidad tan incómoda como las consecuencias derivadas de la analfabetización (Le Maroc raconté par ses femmes. Sexe, idéologie et Islam, 1983). Esta última sería fruto de una sociedad patriarcal legitimada en una interpretación de los fundamentos de la religión islámica cuestionada por la autora (Le harem politique. Le Prophète et les femmes, 1987) y denunciada también por Sumaya Naamane Guessus (Au-delà de toute pudeur: la sexualité féminine au Maroc, 1988). De forma que las reflexiones de al-'Āșimī completarían el escenario trazado por Mernissi y Guessus, entre otras pioneras. 
También presentará algunos elementos en común con obras posteriores. Una de las más importantes por su repercusión en el ámbito de la crítica literaria marroquí fue el ensayo publicado en 1994 por Rašĩda b. Mas'ūd bajo el título de al-Mar'a wa kitāba (La mujer y la escritura). Como señala González (2017: 27-30), las reflexiones de la también escritora y crítica literaria marroquí se encuentran en consonancia con la corriente reivindicativa emprendida por sus compatriotas en décadas anteriores.

El texto de al-'Āṣimī es fiel reflejo de esta coyuntura, en el que el movimiento asociativo femenino y feminista en Marruecos comenzaba a adquirir una cierta presencia (Gómez Camarero, 1995: 3971). En sus páginas se dan cita algunas de las consecuencias y frustraciones generadas por estas primeras reformas entre un sector de la población cuyas aspiraciones se vieron truncadas por las limitaciones de un sistema democrático sui generis. Con unas limitaciones impuestas y siempre controlado desde arriba, no se tuvieron en cuenta las demandas de las marroquíes ni se contó con su participación.

El escenario que plantea al- 'Āṣimī resulta sumamente ilustrativo del carácter cosmético de muchas de las medidas adoptadas durante el denominado proceso de modernización y democratización, cuyas carencias y limitaciones se reflejan en algunos de los discursos e informes oficiales, pero también y sobre todo, en las bases ideológicas que los sustentan.

Asimismo, la metodología del análisis del discurso ha adquirido una gran importancia en la revisión histórica de documentos al entenderlos como una práctica social en una doble dimensión, pues si por un lado reflejan los cambios experimentados (Fairclough, 1992), por el otro actúan como herramienta de interacción social (van Dijk, 2000). Siguiendo esta línea argumental, el texto ofrece numerosas muestras de lo que Fairclough (1995) y van Dijk (1999 y 2016) definen como análisis crítico del discurso, ya que ofrece una visión crítica de las instituciones políticas y sociales creadas y cómo su composición y funcionamiento favorecen el abuso de poder, el dominio y la desigualdad social, entendida esta última también en clave de género.

No obstante, el objetivo fundamental de las siguientes líneas no es reflexionar en torno al marco teórico empleado, sino ofrecer al lector no versado en lengua árabe algunos de los extractos más significativos de la obra y contextualizarlos en el panorama político y social de finales de los años ochenta y principios de los noventa. Este primer objetivo conduce indefectiblemente a analizar los contenidos expuestos, también desde el punto de vista del análisis crítico del discurso, haciendo hincapié en aquellos aspectos que se identifican como parte del marco conceptual de esta disciplina de estudio.

\section{La mujer y la problemática de la democracia. Estudio de la praxis y el discurso}

Las primeras tentativas de una experiencia democrática en Marruecos concitan el interés de al'Āṣimī porque, de igual forma que señalaba en su análisis de la literatura popular, la invisibilización de la mujer en las distintas vertientes del proceso y sus consecuencias constituyen una de las claves que explicarían el fracaso de ésta y de sucesivas reformas:

"Cuando consideré abordar la experiencia democrática en Marruecos me encontré ante numerosas problemáticas, algunas estrechamente vinculadas entre sí, y otras 
que presentaban diferentes características. Entonces comprendí que parte de ellas estaban directamente relacionadas con la mujer, y comencé a recopilar una serie de cuestiones de gran calado." (al-'Āșimī, 1991: 5).

No obstante, la autora es consciente de la envergadura y complejidad que encierra la temática y decide advertir al lector de que se encuentra ante una serie de lineamientos generales en los que se profundizará en posteriores trabajos:

“Por este motivo pensé que era preferible abordar como primer aspecto la dimensión pública y situarla en el marco general de la mujer y la problemática que suscita la experiencia democrática esperando poder abordar sus especificidades en un estudio posterior." (al-'Āṣimī, 1991: 5).

Con estas palabras da comienzo la obra, que se compone de un prólogo, tres capítulos y un epílogo. Y que, pese a lo anunciado por la autora, no ha alcanzado continuidad hasta el momento en posteriores trabajos. Cronológicamente, la publicación se sitúa en los albores del proceso que dará lugar al desarrollo de una narrativa post-colonial fecunda en el estudio de la construcción ideológica del discurso democrático en el país.

La segunda característica es que presenta numerosas limitaciones en el terreno filosófico y conceptual, ya que no estamos ante un estudio académico (carece de bibliografía), ni ante una obra de referencia en el terreno del pensamiento político. Primero, porque su autora no tuvo esa pretensión al concebir el texto, de marcado carácter divulgativo. Y segundo, porque estamos ante una escritora que se expresa habitualmente a través de su obra poética y que de forma excepcional, y como consecuencia de su investigación en la literatura popular, de su experiencia en la vida política, y de su militancia feminista, optó por plasmar sus impresiones en forma de ensayo sin acogerse conscientemente a ninguna corriente de pensamiento.

Aun así, es posible realizar algunas reflexiones en torno a los contenidos, que son consecuencia directa del posicionamiento de la autora ante las reformas políticas acometidas tendentes a la democratización del país. Siguiendo el planteamiento de Macías Amoretti (2018: 3) en su análisis de la historia y el discurso democrático en el pensamiento marroquí, al-'Āṣimī introduce una serie de conceptos en torno a los que se genera el discurso democrático (derechos humanos, justicia social, igualdad, libertad) y aquéllos en torno a los que se genera el significado último del discurso (autoritarismo, corrupción, jerarquía, discriminación).

En la introducción, titulada "Consideraciones sobre la Democracia" (al-'Āṣimī, 1991: 7-18), la autora plantea precisamente esta primera distinción entre los valores que habitualmente se relacionan con el concepto de democracia y la contradicción existente entre ese marco teórico y determinados discursos e instituciones consideradas democráticas en el país magrebí. Estos fragmentos se muestran plenamente coherentes con las declaraciones de 2012 en las que se refería a sus objetivos políticos y en la importancia de conseguir un cambio de mentalidad en la sociedad para lograr la justicia social como eje vertebrador del sistema democrático marroquí (Belqāsim, 2012).

Otro aspecto interesante es el calificativo de "ramificaciones externas" de la democracia que emplea para referirse a las necesidades materiales y a la cooperación exterior. Lejos de erigirse en herramientas del neo-colonialismo económico, para al-'Āṣimī se trata de dos rasgos 
consustanciales a la implantación de un sistema auténticamente democrático que responda a esa concepción teórica antes mencionada, por lo que se presupone que están desprovistos de cualquier fin utilitaristas por parte de otros países. En cualquier caso, supone una alusión directa a la grave situación económica por la que atravesaba el país magrebí en ese momento.

En un segundo bloque (al-'Āșimī, 1991: 13-18) aborda la eterna lucha entre el bien y el mal expresadas en términos de justicia e injusticia social, de democracia y autoritarismo, de equidad y corrupción. Este enfrentamiento es descrito a través del proceso que se inicia con la institución de una serie de valores en torno a la justicia y a la igualdad que se articulan en torno a las instituciones democráticas y culmina con la corrupción de dichos valores y su repercusión en el funcionamiento de las citadas instituciones.

Sin embargo, en este recorrido la autora no plantea las posibles causas de esta degradación del discurso democrático y su deriva hacia valores contrarios a dicho discurso, que sí desarrolla parcialmente en los tres capítulos siguientes bajo el epígrafe "Marruecos como campo de prácticas. Estudio de la praxis y el discurso" (al-'Āṣimī, 1991: 19). Se trata de una alusión intencionada al carácter provisorio y experimental de las medidas y reformas adoptadas, en parte por falta de experiencia previa pero también, y sobre todo, por las reticencias de las elites dominantes a implantar reformas efectivas que pudieran poner en riesgo el poder que ejercían hasta ese momento al regir los destinos del país.

En el primer capítulo, "La visible ausencia de la mujer en el ejercicio democrático" (al- 'Āṣimī, 1991: 23-54), se exponen algunos ejemplos que evidencian esta situación. Con esta finalidad, se abordan en primer lugar los contenidos de ese discurso oficial alejado del originario para después establecer su alcance a través de una serie de planteamientos estructurados en tres ejes.

El primero lo constituye la posición de la mujer en los organismos e instituciones democráticas que la autora califica de "superiores". Con este término se refiere a los Consejos Locales, las Cámaras Profesionales, al Congreso de los Diputados y al Consejo Superior de la Promoción Nacional y del Plan. En concreto, analiza el proceso de creación y la elección de los miembros que los integran para adentrarse posteriormente en sus estructuras y atribuciones desde un punto de vista teórico (fundamentos jurídicos) y práctico (actividades y alcance real de las mismas).

De todo ello se coligen tres conclusiones: que la ausencia de la mujer de las instituciones democráticas no es atribuible a la legislación; que la situación de dichas instituciones tiene su origen en raíces mucho más profundas que parten de la concepción y formulación que se ha hecho de la democracia; y que la presencia y participación de la mujer en la vida política no reviste interés bajo ningún punto de vista en el planteamiento democrático que se está haciendo en el país magrebí, y que por ello resulta especialmente sintomático de las carencias existentes en el diseño y gestión del modelo democrático que se ha adoptado (al-'Āṣimī, 1991: 36).

El segundo capítulo se centra en la ausencia de la mujer en el transcurrir democrático, para lo cual se procede al estudio del discurso que justifica y legitima dicha discriminación. En primer lugar, se explican los argumentos expuestos y se ofrecen ejemplos de las escasas presencias y numerosas ausencias femeninas en la historia política y cultural del país, para terminar comentando algunos de los elementos que actúan como transmisores y perpetuadores de dichas ausencias. 
Entre las presencias, se destaca la cultura del harén, muy visible en la cultura popular, y los testimonios de esa época que contribuirían a transformar lo que en realidad suponía una forma de segregación y de limitación de la libertad de las mujeres en un símbolo de la independencia femenina (al-'Āșimī, 1991, 80-82). Sus investigaciones sobre la literatura popular que dieron origen a su tesis doctoral sirven como base a esta sección y denotarían, además, algunas confluencias con el pensamiento de Mernissi.

En lo concerniente a los elementos que han contribuido a perpetuar la ausencia de la mujer en las instituciones democráticas, al-'Āșimī menciona, entre otros, la crisis de valores éticos y el silencio, que llega a definir en términos de "destrucción", respecto a cualquier huella femenina que pudiera incluirse en la historia oficial del país; una historia mutilada que ha sido y continúa siendo transmitida a generaciones de marroquíes.

En cuanto a los medios e instrumentos que han contribuido a legitimar la dialéctica de la exclusión de la mujer en las instituciones marroquíes, la autora sigue la estela de Mernissi en El harén político y se sirve de algunos pasajes coránicos para defender su posicionamiento. No obstante, a diferencia de Mernissi no emprende una labor de exégesis ni sigue las pautas hermenéuticas que en el feminismo islámico se definen como "yihad de género". En su lugar, se limita a extraer cuatro aleyas (incluyendo un fragmento incompleto y otro alterado respecto al original) y a emplearlas en su sentido más literal y sin comentarios adicionales (al-'Āṣimī, 1991: 105):

“¿Acaso ordenáis a la gente que sea virtuosa y vosotros mismos lo olvidáis, a pesar de que recitáis la [Sagrada] Escritura? ¿Es que no razonáis?” (azora La Vaca, Corán, 2: 44); “[...] Dios no cambia la situación de un pueblo mientras ellos no cambien lo que hay en sus almas" (azora El Trueno, Corán, 13: 11); “iOh, los que creéis! Vuestra responsabilidad es cuidar de vuestras propias almas..." (azora La Mesa, Corán, 5: 105) ${ }^{4}$; y "Cada alma es responsable de lo que hizo" (azora El Arropado, Corán, 74: 38).

Con ellas trata de cuestionar los argumentos que justifican la pervivencia de un régimen patriarcal en virtud de que estaría sustentado por el texto coránico. De esta forma, los versículos adquieren una re-significación en clave feminista que puede ser concebida como revolucionaria en comparación a la interpretación tradicional basada en la segregación y supeditación de la mujer al hombre.

Asimismo, la selección promueve una reflexión en torno a la libertad y los valores éticos sobre los que se está construyendo ese modelo democrático marroquí en el que perviven las actitudes discriminatorias y autoritarias. La autora advierte de los peligros de esta desviación y se muestra vehemente en su rechazo utilizando de nuevo el texto coránico como herramienta (al-'Āṣimī, 1991: 108):

"Así pues, no obedezcas a quienes desmienten. Desearían que fueras condescendiente para serlo ellos también contigo. No obedezcas a ningún vil jurador, al pertinaz difamador, que va sembrando calumnias, a quien impide el bien, al

\footnotetext{
${ }^{4}$ La cita recogida por al-`Asimi (1991: 105) incurre en dos errores respecto al versículo original: la sustitución del pronombre relativo masculino plural (los que) por el sustantivo "nās" (gente) y la elisión del verbo.
} 
violador de la ley, al pecador, al arrogante y, encima, bastardo..." (azora El Cálamo, Corán, 68: 8-13).

El tercer capítulo recoge y amplía algunos de los contenidos expuestos en las páginas anteriores y que quedan circunscritos a las siguientes cuestiones. En primer lugar, la existencia de un movimiento feminista sin historia reconocida ni difundida, pese a su existencia. En segundo término, la estrecha vinculación entre mujer y democracia, de forma que abordar la situación crítica en la que se encuentra social, cultural y políticamente el colectivo femenino es abordar también el intento fallido de instaurar una auténtica democracia en Marruecos. $Y$ como tercer elemento complementario a los anteriores, el incumplimiento de los derechos humanos en el país magrebí.

En esta misma línea, cinco años más tarde Amina Lemrini (1995: 29-30) volvería a denunciar públicamente cómo la práctica totalidad de las mujeres trabajadoras (el índice de población activo femenino se situaba en los años 90 en el 20\%), lo hacían en empleos subalternos sin posibilidad de acceder a los puestos de responsabilidad, evidenciando con ello la pervivencia de la exclusión femenina en las instituciones mencionadas en la obra.

Tras este sucinto recorrido se llega al epílogo, en el que dedica un último epígrafe a sustentar una de sus principales conclusiones: la existencia de una jerarquía política y social distorsionada basada en unos presupuestos culturales y morales que deben ser revisados, pues afectan a la conceptualización e implementación del modelo democrático.

Tomando en consideración esta última afirmación, podría decirse que al-'Āṣimī esboza las principales líneas descriptivas de los tres niveles de narrativa del discurso democrático expuestos por Macías Amoretti (2018: 20): la política, la ética y la sociedad. Los tres ámbitos citados compartirían el acusado desequilibrio basado en la discriminación de género que debe revertirse según la autora, pues es imposible que se instaure un auténtico sistema democrático si está concebido para marginar a la mitad de la sociedad (al-'Āṣimī, 1991: 105).

Asimismo, aborda parcialmente los generadores del discurso (Historia, cambio cultural, ética, Islam, Democracia) y del significado (injusticia, autoritarismo, corrupción) expuestos posteriormente por pensadores de la talla de Muhammad 'Ābid al-Ŷābrī, entre otros, si bien no con la profundidad de análisis ni con el marco teórico-conceptual que éstos manejan.

Desde el punto de vista histórico-político, Hernando de Larramendi y López García (1996: 19) mencionan que las fuentes a las que el estado post-colonial marroquí ha acudido para salvar los sucesivos déficits de legitimidad habrían sido la liberalización política y la re-islamización desde el Estado. El texto de al-'Āșimī evidenciaría el fracaso cometido en 1991 respecto a la liberalización política.

De hecho, la autora señala que las instituciones democráticas en Marruecos han discurrido en dos etapas bien diferenciadas. La primera se habría desarrollado en dos fases: desde 1976 hasta 1983 y desde 1983 hasta 1991. Y la segunda, que daría comienzo en el momento de la publicación de la obra, durante la cual la autora expresa la necesidad de que las mujeres empiecen a formar parte 
de dichas instituciones (al-'Āṣimī, 1991: 21) como signo inequívoco de que se estaría produciendo un cambio en el modelo social.

Con el fin de equilibrar dicho modelo de jerarquía social existente, al-'Āșimī propone tres líneas de actuación. La primera, el desarrollo de una serie de mecanismos que permitan a las mujeres expresar sus ideas y argumentos libremente, sin temor a ser juzgadas por su cuerpo o su reputación. Por ello se hace necesario centrar el debate en los contenidos de las propuestas y no en el género de quien las presenta. En segundo lugar, el establecimiento de unos valores éticos y morales democráticos en los que han de re-educarse tanto a nivel individual como colectivo la sociedad marroquí. $Y$ en tercer término, el cambio de las leyes que prácticamente sacralizan la autoridad ejercida por el individuo y no por la comunidad. La concentración de poder que ello supone desemboca en el ejercicio de un autoritarismo que además de contradictorio respecto a un sistema democrático, resulta perjudicial para su correcta implantación y funcionamiento (al'Āṣimī, 1991: 107).

En este sentido, al-'Āṣimī no sólo expone sus puntos de vista, también aporta soluciones o alternativas intelectuales útiles que contribuyan a implementar unas instituciones que sean coherentes con los elementos generadores del discurso democrático. La autora concluye que esta lucha por la participación de las mujeres en las instituciones democráticas debe continuar bajo el amparo de todas las estructuras y grupos sociales.

También reconoce que el aprendizaje recibido no ha sido debido únicamente a los esfuerzos realizados por las marroquíes. La constancia, el trabajo y la fe en las mujeres y en su causa por parte de aquellos hombres que la autora define como "iluminados" en el mejor sentido del término (al-'Āṣimī, 1991: 108) ha contribuido a que la lucha se inserte en el proceso de democratización del país magrebí.

En palabras de otro gran intelectual marroquí, 'Abd al-Karīm Gallāb (Apud: Macías Amoretti, 2018: 4), reflexionar sobre la identidad, la cultura, la modernidad, la sociedad o el propio pensamiento es hacerlo sobre la democracia. En todos estos ámbitos, el papel de la mujer sigue siendo clave, como pone de manifiesto al-'Āșimī en esta obra y en su propia trayectoria vital y profesional.

\section{Conclusiones}

A tenor de lo expuesto en líneas anteriores cabría colegir que Malīka al-'Āṣimī fue una de las primeras mujeres que hicieron oír su voz en un país anclado durante años en una mentalidad conservadora de tradición patriarcal que aún perdura, y como tal, merece el reconocimiento de las nuevas generaciones que se han unido a la lucha.

Considerada como una de las poetas marroquíes contemporáneas que goza de mayor acogida entre el público y la crítica literaria, su dedicación a promover la visibilización de la mujer marroquí en el terreno artístico y literario le ha llevado a incentivar dicha presencia dentro de un proceso de normalización conducente a la igualdad entre creadores. Y lo mismo cabe decir respecto a la arena política, en la que ha de valorarse su aportación a la integración de otras mujeres y a la adopción de pequeños pero significativos pasos hacia un mayor empoderamiento femenino en Marruecos. 
Definida por Abdellatif Laâbi como "el ejemplo de la intelectual ciudadana" (Laâbi, 2006: 81), Malīka al-'Āṣimī es una destacada militante feminista de la que conviene destacar su coherencia vital. Esta última se ha podido mostrar a través de su labor como docente e investigadora universitaria, parlamentaria y escritora. La confluencia de estos ejes de actuación ejemplifica la transversalidad e interseccionalidad del feminismo marroquí.

Dicha confluencia se refleja en los planteamientos expuestos en al-Mar'a wa iškāliyyat aldìmuqrāțiyya. De carácter fundamentalmente histórico, se trata de uno de los primeros textos en los que se reflexiona sobre los derechos de la mujer en el marco de los valores democráticos promovidos por las instituciones políticas desde comienzos de la década de los noventa. No obstante, se advierten también algunas dosis de análisis sociológico en la búsqueda y explicación de los hechos. Asimismo, desde el punto de vista del análisis crítico del discurso presenta buena parte de las características enunciadas por Van Dijk y revela una intencionalidad manifiesta de interactuar y modificar algunos de los presupuestos que sustentan la mentalidad más tradicional de la sociedad marroquí.

En este sentido, podría considerarse que el texto constituye un precedente de la tendencia que posteriormente alcanzará mayor desarrollo, en el sentido de que se señalan algunos de los elementos clave que hacen del actual sistema político marroquí un modelo fallido de estado plenamente democrático. Con ello, como señala Habashi (2012: 161), se rechazan muchos de los presupuestos ideológicos del post-colonialismo sobre los que se había sustentado el régimen marroquí.

\section{Bibliografía}

EL-AMRANI, Lamiae (2007): "Literatura escrita por mujeres en el Marruecos actual", en ARRIAGA, Mercedes et al. (eds.): Escritoras y pensadoras europeas, Sevilla, ArCiBel, pp. 263-274.

ASIMI, Malika (1981): Documento sin título, en VVAA.: Literatura y pensamiento marroquíes contemporáneos (pp. 405-408). Madrid: Instituto Hispano-Árabe de Cultura.

AL-'ĀṢıMī, Malīka (1987): al-Ḥikāya al-ša'abīya fĩ Marrākuš, Tesis Doctoral, Universidad Mohamed V, Rabat.

(1988a): Kitābāt jāriŷ aswār al-'ālam, Casablanca, 'Uyūn al-Maqālāt.

(1988b): Așwāt ḥanŷara mayyita, Rabat, Manšūrāt al-Risāla.

(1991): Al-mar'a wa iškāliyyat al-dīmuqrāțiyya. Qirā'a fí al-wāqi wa al-jițāb, Casablanca, Ifrīqīya al-Šarq.

(1997): Šay' la-hu asmā', Casablanca, Mu'assasa al-'Arabīya li-I-Našr wa-l-ibdā'.

(2001a): Dimā' al-šams, Casablanca, Dār al-Taqāfa.

(2001b): Nahnnu wa as'ila al-mustaqbal, Rabat, Manšūrāt al-Zaman.

(2008): Kitāb al-'așf, Rabat, Manšūrāt al-Wizāra al-İaqāfa.

(2015): Ašyā' tarāwada-hā, Rabat, Manšūrāt Bayt al-Ši'r fĩ al-Magrib.

(2017): Harrāk al-Rîf. Aktafi bi-hadā, disponible en

http://www.marrakech7.com/index/details/15479/AK [consulta: 20 de agosto de 2018].

BELQĀSIM, 'A. (2012): Ḥiwār ma'a awwal muntajiba magribī-ya al-barlamānīya wa al-kātiba Malīka al-'Āṣimī, disponible en http://rabitato.blogspot.com.es/2012/11/blog-post 1318.html [consulta: 14 de agosto de 2018]. 
BENJELLOUN, Abdelmajid (1976): La mémoire future: Anthologie de la nouvelle poésie du Maroc, París, Maspero.

BENLABBAH, Fatiha (2001): "Asociacionismo femenino en Marruecos", Anuario de Hojas de Warmi, no 12, pp. 9-19, disponible en https://revistas.um.es/hojasdewarmi/article/view/166431 [consulta: 9 de julio de 2018].

BENMSESSAOUD TREDANO, Abdelmoughit (2006): "Transition pre-démocratique, société civile et articulation des pouvoirs au Maroc", en Pérez Beltrán, Carmelo (ed.): Sociedad civil, derechos humanos y democracia en Marruecos, Granada, Editorial Universidad de Granada pp. 51-67.

BERRADA, Mohammed (2008): “Arab North Arica". En Ashour, Radwa; Ghazoul, Ferial J. y RedaMekdashi, Hasna (eds.): Arab Women Writers: A Critical Reference Guide, 1873-1999, El Cairo, The American University in Cairo Press, pp. 235-253.

BOUM, Aomar y PARK, Thomas K. (2016): Historical Dictionary of Morocco, Maryland, Rowman \& Littlefield.

CORTÉS, Julio (1992): El Corán, Londres, Tahrike Tarsile Qur'an.

DABASHI, Hamid (2012): Arab Spring: The End of Postcolonialism, New York, Zed Books, 2012.

FAIRCLOUGH, Norman (1995): Critical discourse analysis, London, Longman.

FAIRCLOUGH, Norman (1992): Discourse and social change, Cambridge, Polity Press.

FELIÚ, Laura (2006): "Le mouvement culturel Amazigh (MCA) au Maroc", en L'Année du Maghreb 2004, pp. 273-286.

FERNÁNDEZ PARRILLA, Gonzalo (2014): "The Challenge of Moroccan Cultural Journals of the 1960s", Journal of Arabic Literature, № 45, vol. 1, pp. 104-128. DOI: https://doi.org/10.1163/1570064x-12341278

GÓMEZ CAMARERO, Carmen (1995): "El movimiento femenino y feminista en Marruecos", en Pérez Beltrán, Carmelo y Ruiz de Almodóvar, Caridad (eds.): El Magreb. Coordenadas socioculturales, Granada, Estudios Árabes Contemporáneos-Adhara, pp. 39-71.

GONZÁLEZ NAVARRO, Ana (2017): "Rachida Benmasud y la feminización del canon a través de la ginocrítica marroquí", Journal of Feminist, Gender and Women Studies, no 6, pp. 23-32, disponible en http://www.rebelion.org/docs/248013.pdf [consulta: 2 de junio de 2018].

GREIMAS, Algirdas Julius (1976): "Hacia una teoría del discurso poético", en Greimas, Algirdas Julien (dir.): Ensayos de semiótica poética, Barcelona, Planeta, pp. 16-29.

EL-HARTI, L. (2008): "Siete poetas marroquíes contemporáneos: Abdellatif Laabi, Malika Assimi, Idriss Issa, Hassan Najmi, Ahmed Assid, Aisha Basry, Yassi Annane”, Caravansari. Revista de poesía contemporánea en lenguas peninsulares y árabe, $\mathrm{n}-1$, pp. 42-48, disponible en http://www.caravansari.com/caravansari numero 1.pdf [consulta: 5 de septiembre de 2018].

HERNANDO DE LARRAMENDI, Miguel y LÓPEZ GARCÍA, Bernabé (1996): Sistemas políticos del Magreb actual, Madrid, Mapfre.

JAY, Salim (2005): Dictionnaire des écrivains marocains, Casablanca, Eddif.

LAÂBI, Abdellatif (2005): La Poésie marocaine de I'Indépendance à nos jours, París, Éditions de La Différence.

LAABI, Abdellatif (2006): La poesía marroquí: de la independencia a nuestros días: antología, Santa Cruz de Tenerife, Ediciones Idea.

LEMRINI, Amina (1995): "L'exclusion des femmes marocaines", en Dore-Audibert, Andrée y Bessis, Sophie (dirs.): Femmes de Méditerranée. Religion, travail, politique, París, Karthala, pp. 21-32.

LÓPEZ GARCÍA, Bernabé (2000): El mundo arabo-islámico contemporáneo. Una historia política, Madrid, Síntesis.

MACÍAS AMORETTI, Juan Antonio (2018): "Narrando alternativas: la historia y el discurso democrático en el pensamiento marroquí contemporáneo (1997-2017)", texto que recoge y 
amplía la ponencia "Intellectual discourse and democracy in Morocco: a textual journey" presentada en el World Congress for Middle Eastern Studies, Sevilla, 17 de julio de 2018. En prensa.

MERNISSI, Fátima (1983): Le Maroc raconté par ses femmes. Sexe, idéologie et Islam, París, Tierce. (1987): Le harem politique. Le Prophète et les femmes, París, Albin Michel.

NAAMANE GUESSOUS, Soumaya (1988): Au-delà de toute pudeur: la sexualité féminine au Maroc, Casablanca, Eddif.

NSOULI, Saleh M. et al. (1995): Resilience and Growth Through Sustained Adjustment: The Moroccan Experience, Washington, International Monetary Fund. DOI: http://dx.doi.org/10.5089/9781557754226.084

OLMEDO SALVADOR, Caterina (2006): "Asociacionismo femenino en Marruecos: un estudio histórico-antropológico", en Pérez Beltrán, Carmelo (ed.): Sociedad civil, derechos humanos y democracia en Marruecos, Granada, Editorial Universidad de Granada, pp. 267-293.

PAREJO FERNÁNDEZ, Ma Angustias. (2005): "Islas de democracia en un mar de transiciones en Marruecos", Hesperia. Culturas del Mediterráneo, no 2, pp. 77-102.

PÉREZ BELTRÁN, Carmelo (2001): "Una aproximación a la sociedad civil de Marruecos", Miscelánea de Estudios Árabes y Hebraicos. Sección Árabe e Islam, no 50, pp. 231-252, disponible en http://www.meaharabe.com/index.php/meaharabe/article/view/231/228 [consulta: 8 de julio de 2018].

(2006): "Introducción", en Pérez Beltrán, Carmelo (ed.): Sociedad civil, derechos humanos y democracia en Marruecos, Granada, Editorial Universidad de Granada, pp. 9-23.

REYES, Antonio (comp.) y Zennan, Abdellatif (trad.) (2007): Antología de la poesía femenina marroquí, Sevilla, Alfar-Ixbilia, pp. 46-49.

VAN DIJK, Teun A. (1999): "El análisis crítico del discurso", Anthropos, no 186, pp. 23-36, disponible en http://www.discursos.org/oldarticles/El\%20an\%E1lisis\%20cr\%EDtico\%20del\%20discurso.pdf [consulta: 11 de julio de 2018].

(2000): El discurso como interacción social. Barcelona: Gedisa, disponible en https://libroschorcha.files.wordpress.com/2017/12/el-discurso-como-interaccic3b3n-social-teunvan-dijk.pdf [consulta: 10 de julio de 2018].

(2016): “Análisis Crítico del Discurso", Revista Austral de Ciencias Sociales, no 30, pp. 203222, disponible en http://revistas.uach.cl/pdf/racs/n30/art10.pdf [consulta: 12 de agosto de 2018].

VELASCO DE CASTRO, Rocío (2012): "Solidaridad y empoderamiento en Marruecos: El testimonio vital de Aicha Channa", en Martín Clavijo, Milagro (ed.): Más igualdad. Redes para la igualdad. Congreso internacional de la Asociación Universitaria de Estudios de las Mujeres, Sevilla, ArCiBel, en $\quad$ pp. 659-670, disponible en http://www.inmujer.gob.es/publicacioneselectronicas/documentacion/Documentos/DE1289.pdf [consulta: 10 de julio de 2018].

(2013): "Marruecos (2003-2013): entre el cambio y la continuidad", en Fernández Rodríguez, Manuela, Bravo Díaz, David y Martínez Peñas, Leandro (eds.): Una década de cambios: de la guerra de Irak a la evolución de la primavera árabe (2003-2013), Valladolid, Asociación Veritas para el Estudio de la Historia, el Derecho y las Instituciones, pp. 111-168, disponible en https://revistaaequitas.files.wordpress.com/2012/02/una-dc3a9cada-de-cambios-1.pdf [consulta: 10 de julio de 2018].

(2016): “Los elementos vertebradores del Marruecos contemporáneo: dimensión política y jurídico-religiosa”, en Velasco de Castro, Rocío, Fernández Rodríguez, Manuela y Martínez Peñas, 
Leandro (eds.): Religión, derecho y sociedad en la organización del estado, Valladolid, Asociación Veritas para el Estudio de la Historia, el Derecho y las Instituciones, pp. 219-254, disponible en http://www.omniamutantur.es/wp-content/uploads/LIBRO-RELIGION-DERECHO-Y-SOCIEDAD-1-

278.pdf [consulta: 14 de agosto de 2018].

(2017): "Las mujeres marroquíes: de la lucha anti-colonial a la lucha por la igualdad de género", en González, Rocío et al. (eds.): Déclinaisons des espaces féminins de l'après-conflit, Limoges, Presses Universitaires de Limoges, pp. 59-72.

(2017): "Malika al-'Asimi: el feminismo como compromiso político y literario en el Marruecos contemporáneo", en Romano, Yolanda y Velázquez, Sara (coords.): Las inéditas: voces femeninas más allá del silencio, Salamanca, Servicio de Publicaciones de la Universidad de Salamanca, pp. 651-664, disponible en

https://gredos.usal.es/ispui/bitstream/10366/138833/1/Las\%20in\%C3\%A9ditas voces\%20femeni nas\%20m\%C3\%A1s\%20all\%C3\%A1\%20del\%20silencio.pdf [consulta: 26 de noviembre de 2018].

AL-WAZZĀNī, Ḥassan (ed.) (1993): Dalīl al-kuttāb al-magāriba a'ḍā' Ittihāo Kuttāb al-Magrib, Rabat, Manšūrāt Ittiḥād Kuttāb al-Magrib. 